\title{
REVIEW ARTICLE OPEN Recent advances in cell sheet technology for bone and cartilage regeneration: from preparation to application
}

\author{
Yuezhi Lu ${ }^{1}$, Wenjie Zhang ${ }^{1}$, Jie Wang ${ }^{1}$, Guangzheng Yang ${ }^{1}$, Shi Yin ${ }^{1}$, Tingting Tang ${ }^{2}$, Chunhua Yu ${ }^{1}$ and Xinquan Jiang ${ }^{1}$
}

Bone defects caused by trauma, tumour resection, infection and congenital deformities, together with articular cartilage defects and cartilage-subchondral bone complex defects caused by trauma and degenerative diseases, remain great challenges for clinicians. Novel strategies utilising cell sheet technology to enhance bone and cartilage regeneration are being developed. The cell sheet technology has shown great clinical potential in regenerative medicine due to its effective preservation of cell-cell connections and extracellular matrix and its scaffold-free nature. This review will first introduce several widely used cell sheet preparation systems, including traditional approaches and recent improvements, as well as their advantages and shortcomings. Recent advances in utilising cell sheet technology to regenerate bone or cartilage defects and bone-cartilage complex defects will be reviewed. The key challenges and future research directions for the application of cell sheet technology in bone and cartilage regeneration will also be discussed.

International Journal of Oral Science (2019)11:17; https://doi.org/10.1038/s41368-019-0050-5

\section{INTRODUCTION}

Bone defects caused by various aetiologies, such as trauma, tumours, infection and congenital deformities, together with articular cartilage defects and osteochondral complex defects caused by trauma and degenerative diseases, are common clinical diseases that significantly affect the patient's quality of life. Repair and regenerating these defects in bone and cartilage is a considerable challenge for clinicians. ${ }^{1-4}$ There has been significant progress in the development of tissue engineering over the past two decades, which has brought new hope for the regenerative treatment of bone and cartilage defects. ${ }^{5,6}$ Conventional tissue engineering techniques mainly include the injection of a cell suspension and the transplantation of scaffolds seeded with cells. ${ }^{7}$ However, several problems remain to be solved. With the injection of a cell suspension, locating the injected suspension and controlling the shape and size of the cell suspension after injection is difficult. The number of cells that can be delivered by one injection is quite limited, and the cells are easily lost after injection. Additionally, a uniform distribution of the injected suspension is difficult to achieve. Thus far, the cell injection technique cannot meet the requirements for regenerating tissue morphology and function. An ideal biodegradable scaffold material that can efficiently promote cell adhesion, proliferation and extracellular matrix (ECM) secretion with suitable mechanical properties is still being sought by researchers. ${ }^{8}$ Existing scaffold materials usually have several limitations, such as insufficient biological activity, unstable degradation rate and immunogenicity, resulting in immune responses and inflammation after transplantation. Cell-material interactions are usually uncontrollable and may result in high cell mortality. ${ }^{9}$ Cell-cell interactions and ECM formation contribute to maintaining tissue stability. Conventional tissue engineering techniques for harvesting cells by trypsin digestion damage cell-cell interactions, cell-ECM interactions and cell membrane proteins, resulting in decreased cell adhesion and proliferation.

To overcome the shortcomings of conventional tissue engineering technology, cell sheet technology, an alternative approach, has gradually attracted the attention of researchers in recent years. Cell sheet technology was developed based on a novel technique for culturing and harvesting cells using temperatureresponsive culture dishes, which was first reported in $1990 .^{10,11}$ The hydrophilic and hydrophobic properties of the temperaturesensitive material poly( $N$-isopropylacrylamide) (PIPAAm) could be altered by changing the temperature, resulting in control over cell attachment and detachment. ${ }^{12}$ Cell sheet technology can be used to harvest cells without utilising proteolytic enzymes, such as trypsin, or chelating agents, such as ethylenediaminetetraacetic acid. Thus the cell-cell junctions, ECM and cell sheet structure are effectively preserved, allowing the constructed tissue to have a high cell density and a uniform cell distribution and thus to mimic native tissue more closely. In addition, cell sheets are prepared by the formation of cell-cell junctions and the secretion of ECM and are free from the limitations of scaffold materials, such as the immune and inflammatory reactions caused by scaffold implantation, tissue collapse caused by a fast degradation rate and compromised tissue formation caused by a slow degradation rate. ${ }^{13-18}$ The application of this technology in bone and cartilage regeneration has been widely studied. On the one hand, cell

\footnotetext{
${ }^{1}$ Department of Prosthodontics, Shanghai Ninth People's Hospital, College of Stomatology, Shanghai Jiao Tong University School of Medicine; National Clinical Research Center for Oral Diseases; Shanghai Engineering Research Center of Advanced Dental Technology and Materials; Shanghai Key Laboratory of Stomatology \& Shanghai Research Institute of Stomatology, Shanghai, China and ${ }^{2}$ Shanghai Key Laboratory of Orthopaedic Implants, Department of Orthopaedic Surgery, Shanghai Ninth People's Hospital, Shanghai Jiao Tong University School of Medicine, Shanghai, China

Correspondence: Chunhua Yu (yuchunhua656663@163.com) or Xinquan Jiang (xinquanj@aliyun.com)

These authors contributed equally: Yuezhi Lu, Wenjie Zhang
}

Received: 28 January 2019 Revised: 8 March 2019 Accepted: 10 April 2019

Published online: 21 May 2019 
sheets can be used without scaffolds for bone and cartilage regeneration; thus they more closely mimic native tissue and avoid the limitations and potential problems of scaffolds. ${ }^{19,20}$ On the other hand, cell sheets can also be used in combination with various scaffolds and may be a better choice than traditional scaffolds seeded with cell suspensions because cell sheets can effectively preserve cell-cell junctions and ECM. ${ }^{21,22}$

Several widely used cell sheet preparation systems, including traditional methods, and recent improvements in these methods, as well as their advantages and shortcomings, will be reviewed. Recent advances in the application of cell sheet technology for the repair and regeneration of bone and cartilage defects will also be reviewed. Furthermore, the key limitations of cell sheet applications in bone and cartilage regeneration, along with directions for future research, will be discussed.

\section{PREPARATION OF CELL SHEETS}

A variety of systems can be used to construct cell sheets, including temperature-responsive, electro-responsive, photo-responsive, pH-responsive, mechanical, and magnetic systems. ${ }^{18,23}$ With continuous advances in cell sheet technology in recent years, approaches to optimising the preparation of cell sheets have been proposed based on these systems (Table 1).

\section{Temperature-responsive systems}

The first proposed systems were temperature-responsive systems, which are currently the most widely used for cell sheet preparation. ${ }^{24}$ The temperature-sensitive material PIPAAm, which has a critical temperature of $32{ }^{\circ} \mathrm{C}$, is covalently bound to the bottom of a cell culture dish. When cells are cultured in the typical $37^{\circ} \mathrm{C}$ environment, PIPAAm exhibits hydrophobic properties, which facilitate cell adhesion and proliferation to promote cell sheet formation. When the temperature is below $32^{\circ} \mathrm{C}$, PIPAAm exhibits hydrophilic properties, and the adhered cell sheet can be completely separated from the culture dish via the formation of a hydration layer between the surface of the culture dish and the cell sheet. $^{25}$ Many improvements to traditional temperatureresponsive systems have been proposed recently. ${ }^{26}$

To accelerate the formation of cell sheets, biomolecules can be utilised to promote cell adhesion or proliferation. Immobilising insulin (INS) on temperature-responsive culture dishes shortened the period of cell sheet formation by promoting cell proliferation, ${ }^{27}$ and immobilising the synthetic cell adhesion peptide ArgGly-Asp-Ser (RGDS) on temperature-responsive culture dishes accelerated cell sheet formation by promoting cell adhesion. ${ }^{28}$

Several improved systems have been developed to shorten the cell sheet detachment time, which could permit further complex manipulation of cell sheets and prevent potential damage to cell viability from long exposures to low, non-physiological temperatures. PIPAAm was grafted onto a porous membrane (PM) by electron beam (EB) irradiation to form a PIPAAm-PM substrate for cell sheet preparation. Compared with the traditional PIPAAm substrate, the PIPAAm-PM substrate showed a decrease in cell sheet detachment time from approximately 75 to $30 \mathrm{~min}$ at $20^{\circ} \mathrm{C}$. ${ }^{29}$ Furthermore, the co-grafting of poly(ethylene glycol) (PEG) with PIPAAm onto the PM by EB irradiation to form a PIPAAm (PEG)-PM substrate was proposed and ultimately shortened the cell sheet detachment time to $19 \mathrm{~min}$ at $20^{\circ} \mathrm{C}^{30} 2$ Carboxyisopropylacrylamide (CIPAAm) was synthesised with a similar side chain structure as that of $\mathrm{N}$-isopropylacrylamide (IPAAm) and a functional carboxylate group. A P(IPAAm-coCIPAAm) substrate was developed to accelerate cell sheet detachment by reducing the exposure time to $35 \mathrm{~min}$ at $20^{\circ} \mathrm{C} .{ }^{31}$ A temperature and saccharide dual-responsive system consisting of both PIPAAm and the saccharide-sensitive material poly(3acrylamidophenylboronic acid) was proposed for cell sheet preparation. Cell sheets could be harvested more efficiently by simultaneously reducing the temperature and increasing the saccharide concentration. The exposure time at $20^{\circ} \mathrm{C}$ for cell sheet detachment was shortened to within $30 \mathrm{~min}$ in $10 \mathrm{~g} / \mathrm{L}$ fructose. ${ }^{32} \mathrm{~A}$ small amount of 3-aminopropyltriethoxysilane (APTES) was utilised to develop a PIPAAm-APTES substrate, which remarkably shortened the detachment time of cell sheets to within $2.5 \mathrm{~min}$ in cold culture medium and improved cell adhesion and proliferation simultaneously. ${ }^{33}$

The incorporation of specific structures into cell sheets is of great importance for mimicking the complex architecture of native tissues and has drawn the attention of researchers. Cell patterning or micropatterning technology has been applied in cell sheet preparation systems. ${ }^{34,35}$ A patterned, bio-functional and temperature-responsive system was fabricated using EB patterning and appropriate metal masks, resulting in the formation of a surface pattern of carboxyl-functional thermo-responsive polymers; this process was followed by site-selective bio-functionalisation with RGDS-INS biomolecules. Cell sheet formation using this system was improved by the promotion of cell adhesion and proliferation, but the detachment time was prolonged to $>3 \mathrm{~h}$ at $20{ }^{\circ} \mathrm{C} .{ }^{36} \mathrm{~A}$ dual temperature-responsive substrate for the preparation of patterned cell sheets containing two different cell types was developed via the patterned polymerisation of $n$-butyl methacrylate into PIPAAm using EB irradiation. ${ }^{37} \mathrm{~A}$ temperatureresponsive system for the preparation of micropatterned cell sheets was proposed by Isenberg et al. The polystyrene substrate for cell sheet preparation was micropatterned by hot embossing with polydimethylsiloxane moulds containing an array of parallel grooves and then grafted with PIPAAm. ${ }^{38} \mathrm{~A}$ similar micropatterned substrate was used to prepare monolayered cell sheets with micropatterns. ${ }^{39,40}$ Williams et al. developed a temperatureresponsive system combined with a microcontact printing technique for the preparation of aligned cell sheets. Lanes were formed on the PIPAAm substrate by microcontact printing of fibronectin (FN) using a patterned stamp. Cells incubated in a serum-free environment preferentially adhered to the lanes containing $\mathrm{FN}$, resulting in ordered alignment. With the addition of serum, the cells expanded into the regions without FN to form a cell sheet. A patterned monolayered cell sheet was then harvested by reducing the temperature. ${ }^{41} \mathrm{~A}$ micropatterned and co-cultured cell sheet preparation system was developed by microcontact printing of $\mathrm{FN}$, followed by the seeding of one type of cell in serum-free conditions and the seeding of another type of cell in the presence of serum. ${ }^{42}$

For application in bone and cartilage regeneration, commercial temperature-responsive culture dishes were used to culture cells, such as mesenchymal stem cells (MSCs), chondrocytes and synovial cells. After the cells were cultured for several days or weeks to form cell sheets, the temperature-responsive culture dishes were exposed to $20^{\circ} \mathrm{C}$ or room temperature for a period of time, and polyvinylidene fluoride (PVDF) membranes or forceps were used to harvest the cell sheets. ${ }^{20,21,43,44}$

\section{Electro-responsive systems}

A new electro-responsive system for cell sheet preparation was proposed by Guillaume-Gentil et al. The cell sheet was formed by growing cells to confluence on a thin polyelectrolyte film. Then the cell sheet was detached from the polyelectrolyte substrate with electrochemical control, such as by applying a positive potential for electrochemical polarisation, or spontaneously without electrochemical control. ${ }^{45}$ Inaba et al. proposed another electro-responsive system for cell sheet preparation involving a gold surface modified with a self-assembled monolayer of alkanethiol and Arg-Gly-Asp (RGD) peptides. Cell sheets formed on the substrate and then could be harvested within $10 \mathrm{~min}$ by the application of a negative electrical potential. ${ }^{46}$ To alleviate the problem of potentially harmful chemicals used in the electroresponsive system remaining in the cell sheets, leading to an 


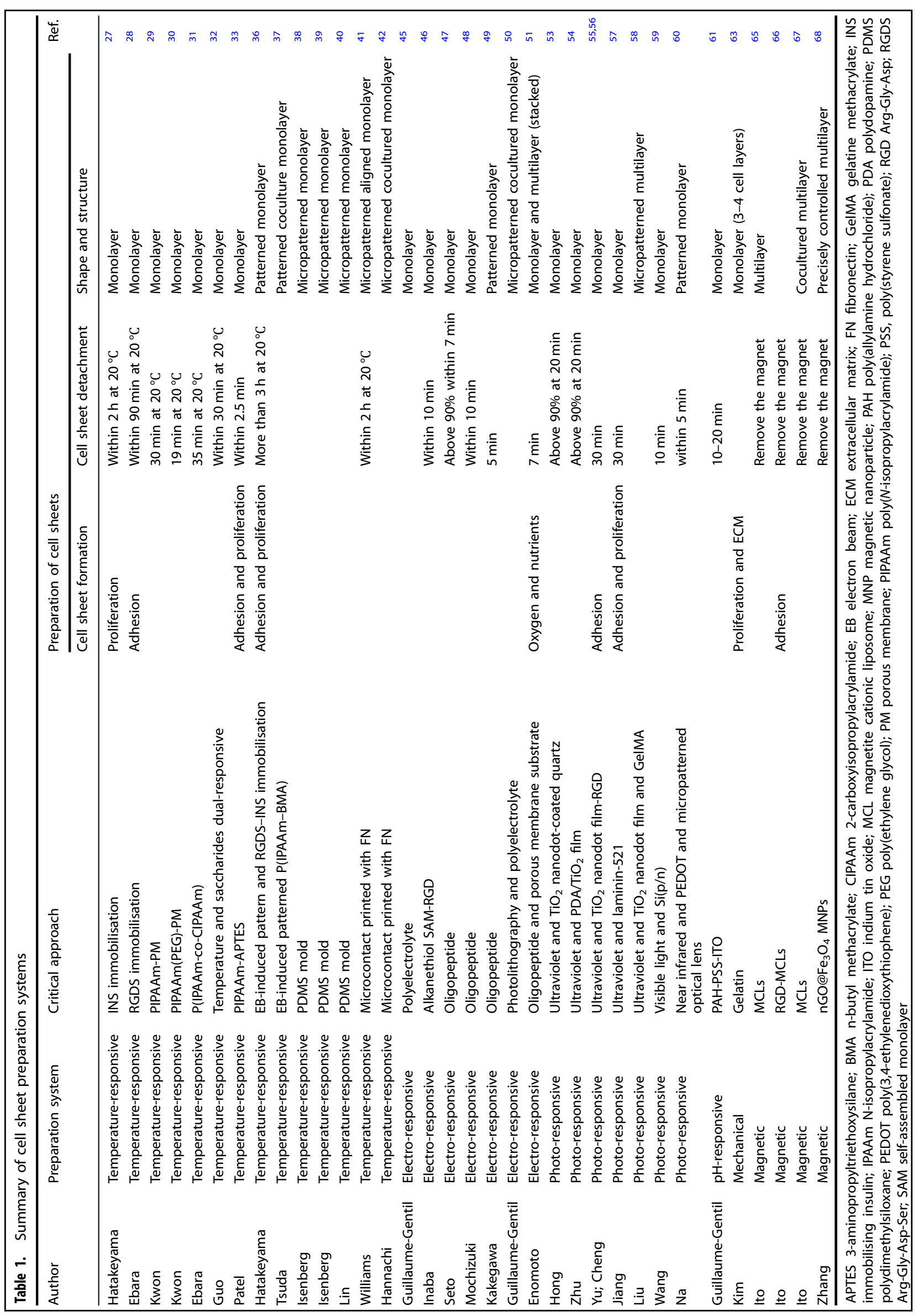


inflammatory response upon application, an oligopeptide containing a cell-adhesion domain, RGD, in the centre and cysteine residues at both terminals was utilised to modify the gold surface. The cell sheets were also detached by the application of a negative electrical potential. ${ }^{47}$ Similar electro-responsive systems for cell sheet preparation were developed using oligopeptides and a negative electrical potential. ${ }^{48,49}$ Cell micropatterns could be transferred to a hydrogel by means of cell-adhesive and cellrepulsive micropatterned oligopeptides. ${ }^{49}$ An electrochemically switchable system for the preparation of micropatterned heterotypic cell sheets was proposed; the system combined photolithographic processing and the local electrochemical dissolution of polyelectrolytes. ${ }^{50}$ A porous gold-coated membrane substrate that improved oxygen and nutrient supply was covered with an oligopeptide layer and utilised as an electro-responsive system for cell sheet preparation. A monolayered cell sheet could be detached in $7 \mathrm{~min}$ by the application of a negative electrical potential, and multilayered structures could be formed by subsequent stacking. ${ }^{51}$ Most studies have mainly focused on electro-responsive systems for cell sheet preparation for application in vascularised tissues, and the application of such systems in bone and cartilage regeneration has not been reported thus far. ${ }^{47,48,52}$ The specific culture substrates and devices needed in the electro-responsive system might be obstacles for widespread application.

\section{Photo-responsive systems}

A photo-responsive system for cell sheet preparation based on ultraviolet light-mediated changes in the hydrophilicity and hydrophobicity of the culture substrate was proposed by Hong et al. The cells were cultured on a titanium dioxide $\left(\mathrm{TiO}_{2}\right)$ nanodot-coated quartz substrate and formed a cell sheet. More than $90 \%$ of the cells could be detached from the substrate by the application of $365-\mathrm{nm}$ ultraviolet illumination for 20 min. ${ }^{53} \mathrm{~A}$ polystyrene substrate covered with a composite polydopamine/ $\mathrm{TiO}_{2}$ film was applied for cell sheet preparation. The application of $365-\mathrm{nm}$ ultraviolet illumination for $20 \mathrm{~min}$ allowed the detachment of $>90 \%$ of fibroblasts and $>77 \%$ of osteoblasts from the substrate. ${ }^{54} \mathrm{~A} \mathrm{TiO}_{2}$ nanodot film with surface-immobilised RGD was proposed for cell sheet preparation and was shown to promote cell sheet formation by improving cell adhesion, and $365-\mathrm{nm}$ ultraviolet illumination for $30 \mathrm{~min}$ prompted cell sheet detachment. $^{55,56}$ Immobilising human recombinant laminin-521 on a $\mathrm{TiO}_{2}$ nanodot film could promote cell sheet formation by improving cell adhesion and proliferation, and these cell sheets could be harvested by $365-\mathrm{nm}$ ultraviolet illumination for 30 min. $^{57}$ A photo-responsive system for the preparation of micropatterned multilayered cell sheets was developed using a $\mathrm{TiO}_{2}$ nanodot film and photo-cross-linkable gelatine methacrylate (GelMA). Photomask-assisted 254-nm ultraviolet illumination was used to micropattern a $\mathrm{TiO}_{2}$ nanodot film, and $365-\mathrm{nm}$ ultraviolet illumination was used to harvest the cell sheet. The photo-crosslinkable GeIMA was used to transfer and stack monolayer cell sheets into a multilayer structure. ${ }^{58} \mathrm{~A}$ visible light-responsive system for cell sheet preparation was proposed by Wang et al. The cell sheets could be detached from silicon wafer substrates with $\mathrm{p} / \mathrm{n}$ junctions $(\mathrm{Si}(\mathrm{p} / \mathrm{n}))$ after $10 \mathrm{~min}$ of illumination with lowenergy visible light. ${ }^{59} \mathrm{Na}$ et al. proposed a photo-responsive system for cell sheet preparation based on near infrared (NIR) light, which is highly transmissive through tissues and safer at an appropriate intensity than ultraviolet and visible light. Owing to the high photothermal efficiency of the poly(3,4-ethylenedioxythiophene) (PEDOT) substrate and the photothermal pattern formed by the diffraction of NIR light through a micropatterned optical lens, cell sheets with various patterns could be harvested within 5 min (Fig. 1). ${ }^{60}$
pH-responsive systems

A pH-responsive system for cell sheet preparation was proposed by Guillaume-Gentil et al. Human placenta-derived MSCs were seeded on a $\mathrm{pH}$-responsive substrate, which was obtained via layer-by-layer deposition of cationic poly(allylamine hydrochloride) and anionic poly(styrene sulfonate) on conductive indium tin oxide electrodes. Then a monolayered cell sheet could be harvested by decreasing the local or global $\mathrm{pH}^{61}$ However, the change in $\mathrm{pH}$ might be detrimental to the physical conditions of the cells; thus this type of system is rarely applied in cell sheet preparation. $^{18}$

\section{Mechanical systems}

Mechanical systems may be easy to prepare a cell sheet without specific culture substrates or techniques, but the required manipulation can be challenging. While few studies have been conducted on simple mechanical techniques, these techniques have been widely used to prepare cell sheets for application. To form an osteogenic or chondrocytic cell sheet, MSCs or chondrocytes were cultured in osteogenic or chondrogenic medium for several days or weeks. ${ }^{62-64}$ When the cells formed a contiguous cell sheet, a cell scraper could be used to lift the cell sheet inward with gentle scraping from the periphery in phosphate-buffered saline. ${ }^{19}$ Forceps have also been used to mechanically peel off and detach cell sheets. ${ }^{62}$ A novel mechanical system for the preparation of osteogenic cell sheets involving the addition of gelatine to osteogenic medium was proposed. Compared to the conventional osteogenic cell sheet, the gelatine-induced osteogenic cell sheet had great cell proliferation and abundant ECM, resulting in a thick and strong cell sheet. ${ }^{63}$

\section{Magnetic systems}

A magnetic system for cell sheet preparation was first introduced by Ito et al. Magnetite cationic liposomes (MCLs) with a positive surface charge for improved adsorption were taken up by cells. Multilayered sheets of MCL-labelled cells were formed in an ultralow-attachment plate via magnetic attraction. The cell sheets were detached from the plates by removing the magnetic field and then harvested with a magnet. ${ }^{65}$ A culture surface coated with RGD peptide-conjugated MCLs (RGD-MCLs) by magnetic attraction was proposed for cell sheet preparation. A contiguous cell sheet containing RGD-MCLs was formed by incubating cells on the RGDMCL substrate, which facilitated cell adhesion, and was then detached by removing the magnet. ${ }^{66}$ Multilayered cell sheets containing heterotypic co-cultured cells labelled with MCLs were fabricated by the application of magnetic force. ${ }^{67}$

Recently, our group developed a magnetic system for preparing cell sheets based on the cellular uptake of $\mathrm{Fe}_{3} \mathrm{O}_{4}$ magnetic nanoparticles (MNPs) coated with nanoscale graphene oxide ( $\mathrm{nGO} @ \mathrm{Fe}_{3} \mathrm{O}_{4}$ ). The $\mathrm{nGO} @ \mathrm{Fe}_{3} \mathrm{O}_{4}$ MNPs could be easily and rapidly taken up by dental pulp stem cells (DPSCs), MC3T3-E1 cells, bone marrow-derived mesenchymal stem cells (BMSCs), chondrocytes and human umbilical vein endothelial cells (HUVECs) (Fig. 2a). Multilayered cell sheets were easily and rapidly constructed via magnetic attraction (Fig. 2 b). In addition to the advantage of easy and rapid preparation of multilayered cell sheets, the magnetic system could precisely control cell sheet shape and structure. Cell sheets with different shapes were formed using two or four magnets (Fig. 2c). A monkey face-like cell sheet pattern was formed using three hollow cylindrical magnets (Fig. 2d). The separate addition of two types of cells resulted in a cell sheet with a bilayered structure (Fig. 2e). In addition, one cell sheet could be inlaid within another cell sheet by simultaneously changing both the cell type and magnet pattern (Fig. 2f). Moreover, the cell sheet thickness could be controlled by the repeated addition of cells (Fig. $2 \mathrm{~g}$ ). ${ }^{68}$ 


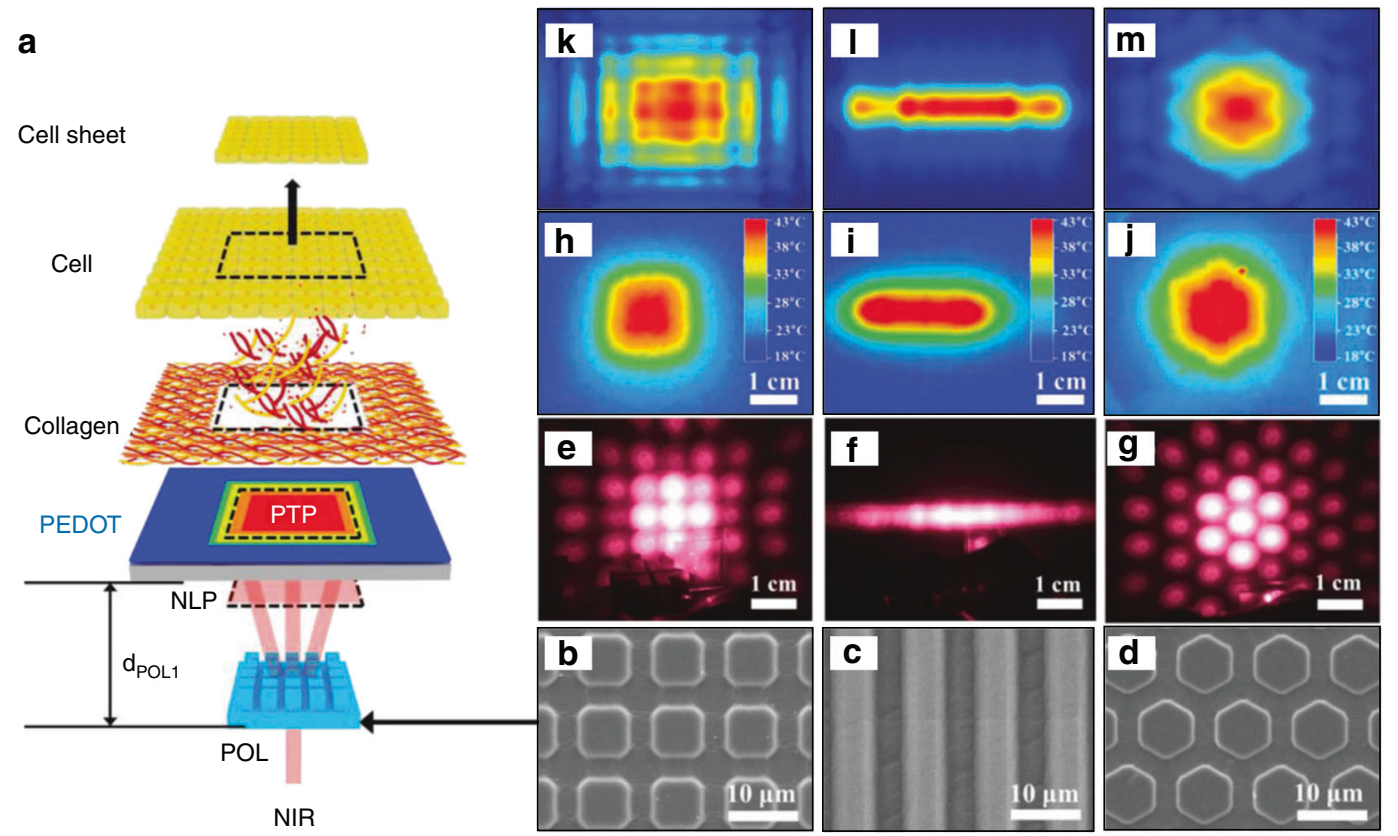

Fig. 1 A photo-responsive system for the preparation of micropatterned cell sheets. a A schematic illustration for the formation of an near infrared (NIR) light pattern (NLP), a photothermal pattern (PTP), and harvesting of a square-type cell sheet using an optical setup including an NIR laser and patterned optical lens (POL). b-d Field-emission scanning electron microscopic images for micropatterned POLs with $\mathbf{b}$ square, c linear, and $\mathbf{d}$ hexagonal patterns. e-g Photographic images of NLPs observed by a digital camera equipped with a visible filter generated from the e square, $\mathbf{f}$ line, and $\mathbf{g}$ hexagon POLs of $\mathbf{b}-\mathbf{d}$, respectively. $\mathbf{h}-\mathbf{j}$ Thermal images obtained for the PTP on the PEDOT substrate generated from the corresponding NLP of $\mathbf{e}-\mathbf{g}$, respectively. $\mathbf{k}-\mathbf{m}$ The finite-difference time-domain calculation result of NLPs using the experimental parameter of the corresponding POL of $\mathbf{b}-\mathbf{d}$, respectively (adapted from ref. ${ }^{60}$ with permission)

\section{APPLICATION OF CELL SHEET TECHNOLOGY IN BONE AND CARTILAGE REGENERATION}

With the rapid development of cell sheet technology, cell sheets have been applied in the regeneration of multiple tissues and organs, such as the heart, liver, kidney, cornea, bladder, oesophagus, trachea, tendon, periodontium, bone and cartilage. ${ }^{69-76}$ In this review, we focus on recent progress in the application of cell sheet technology in bone and cartilage regeneration (Table 2). Although various systems have been developed for cell sheet preparation, temperature-responsive and mechanical systems are the most widely used systems to prepare cell sheets for bone and cartilage regeneration. For the application of temperature-responsive systems in preparing cell sheets, commercial temperature-responsive culture dishes were used to culture cells, such as MSCs, chondrocytes and synovial cells. Cell sheets formed after several days or weeks in culture in temperature-responsive culture dishes and were harvested using PVDF membranes or forceps upon exposure to $20^{\circ} \mathrm{C}$ or room temperature for a period time..$^{20,21,43,44}$ With regard to the preparation of cell sheets using mechanical systems, MSCs, HUVECs or chondrocytes were cultured in induction medium for several days or weeks to form contiguous cell sheets; then cell scrapers or forceps were utilised to lift or peel off the cell sheets. $^{62,64}$

Progress in the application of cell sheet technology in bone regeneration

The application of cell sheets alone in ectopic sites or bone defects has shown promising results. After osteogenic induction, rat BMSCs were prepared into cell sheets using a mechanical system and then subcutaneously transplanted into the rat thigh. New bone formation was promoted without scaffolds. ${ }^{19}$ In another study, the mechanical system was used to prepare cell sheets of rabbit BMSCs, and then these sheets were transplanted into subcutaneous pockets of nude mice. The formation of new bone without the use of scaffold was facilitated by BMSC sheets alone. ${ }^{77}$
The transplantation of multilayered human MSC sheets prepared by the magnetic system into cranial bone defects in nude rats resulted in the formation of new bone surrounded by osteoblastlike cells in the defects. ${ }^{78}$ The preparation of osteogenic cell sheets by a mechanical system and the transplantation into the site of maxillofacial bone defects using a rat mandibular symphysis model enhanced new bone formation. ${ }^{79}$ Fracture healing is normally a spontaneous process that involves initial inflammation, followed by callus formation and finally bone remodelling. However, in some cases, delayed bone union and nonunion may occur due to complex factors, such as disruptions in the biological or mechanical environment. ${ }^{80}$ The application of cell sheets alone in these situations of compromised fracture healing has also shown promising results. A series of studies examined the use of osteogenic cell sheets of rat BMSCs created using mechanical systems for the treatment of fracture nonunion and critical fracture healing. The transplantation of osteogenic cell sheets into fractured rat femurs enhanced bone formation at the fracture site and resulted in stable bone union. ${ }^{81}$ The injection of osteogenic cell sheets into a rat femoral critical fracture healing model enhanced bone regeneration and finally led to bone union. ${ }^{82} \mathrm{Ma}$ et al. wrapped osteogenic pre-differentiated rabbit BMSC sheets around a 2-mm mandibular fracture gap and observed an improvement in delayed bone fracture healing and a reduction in the amount of fibrous tissue at the fracture site. ${ }^{83}$

Intact cell sheet formation relies on cell-cell connections and the ECM secreted by cells. However, as cell sheets have poor mechanical properties, repairing bone defects with cell sheets alone remains a challenge. Thus, many studies have investigated the repair of bone defects by combining cell sheets prepared by mechanical or temperature-responsive systems with scaffolds, which could provide initial mechanical and spatial support. In a study by Zhou et al., multilayered porcine BMSC sheets were harvested after 1-2 weeks of osteogenic induction and then wrapped around pre-seeded polycaprolactone-calcium phosphate (PCL-CaP) scaffolds to form cell sheet scaffold constructs. ${ }^{84}$ 


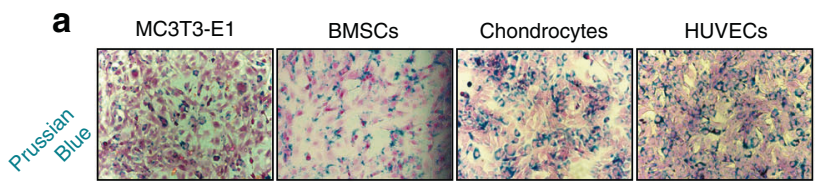

b

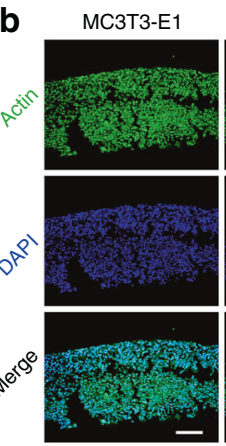

c

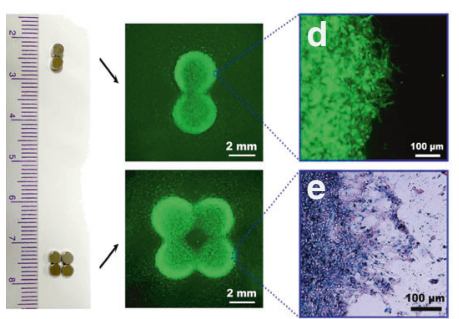

Chondrocytes

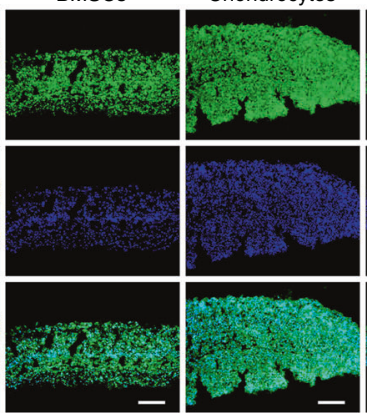

HUVECs

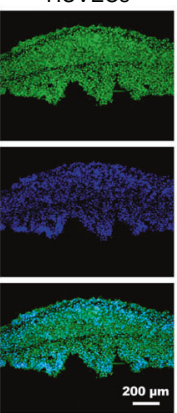

j
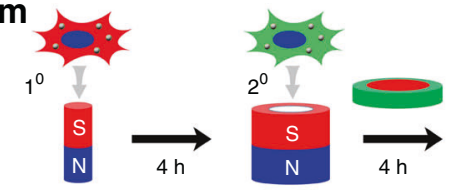
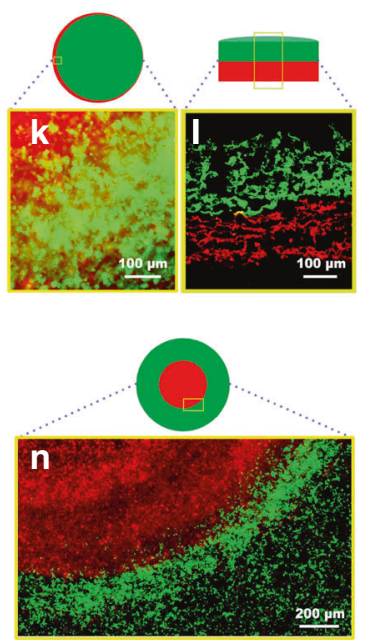
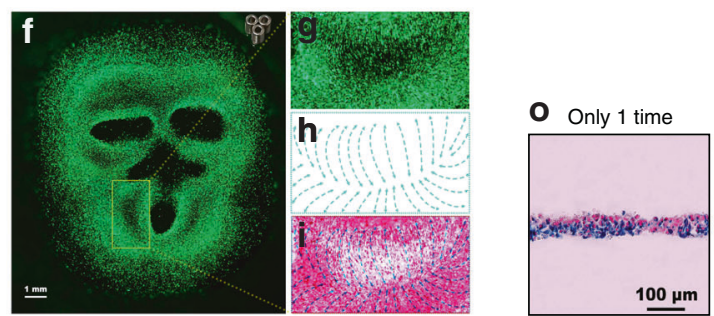

Repeat 2 times

Repeat 5 times

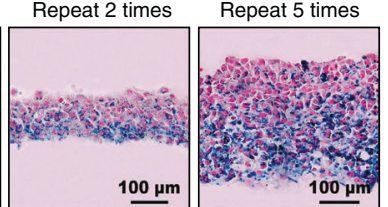

Fig. 2 A magnetic system for cell sheet preparation based on the cellular uptake of $\mathrm{nGO} @ \mathrm{Fe}_{3} \mathrm{O}_{4}$. a MC3T3-E1 cells, bone marrow-derived mesenchymal stem cells (BMSCs), chondrocytes, and human umbilical vein endothelial cells (HUVECs) were incubated with nGO@Fe $\mathrm{O}_{4}$ magnetic nanoparticles (MNPs). Prussian blue staining was used to visualise the distribution of the MNPs. The b MC3T3-E1 cells, BMSCs, chondrocytes, and HUVECs were attracted by the magnetic force to form multilayer cell sheets. c The magnet pattern controlled the shape of the cell sheets. d Cell accumulation was observed at the marginal region of the cell sheet. e The marginal region of the cell sheet was observed after $24 \mathrm{~h}$ of culture with Prussian blue staining. f A monkey face-like cell sheet pattern was fabricated via three hollow cylinder magnets. The local region surrounded by the yellow rectangular frame is magnified and presented in $\mathbf{g}$. $\mathbf{h}$ The cells were arranged in regular continuous curves. i A merged image of the cell distribution and the characteristic curves. $\mathbf{j}$ Schematic illustration of the fabrication strategy to form bilayer cell sheets. $\mathbf{k}$ The accumulation of GFP+ cells on the RFP+ cell sheet was observed. I The bilayer cell sheets were observed after $24 \mathrm{~h}$ of culture. $\mathbf{m}$ Schematic illustration of the strategy to fabricate inlaid cell sheets. $\mathbf{n}$ A clear boundary line between the GFP + cells and the RFP+ cells was observed. o Prussian-blue-stained paraffin sections of cell sheets fabricated via repeated cell seeding. (Adapted from ref. ${ }^{68}$ with permission.)

New cortical and cancellous bone formed within the cell sheet scaffold constructs after subcutaneous implantation into nude rats. Ma et al. wrapped osteogenic pre-differentiated cell sheets derived from rabbit BMSCs around porous beta-tricalcium phosphate ( $\beta$-TCP) scaffolds. Subcutaneous implantation of these cell sheet scaffold constructs into rabbits resulted in superior ectopic bone formation. ${ }^{83} \beta$-TCP scaffolds containing BMSCs were wrapped in osteogenic matrix BMSC sheets to form BMSC/TCP/ sheet constructs. The subcutaneous implantation of these constructs, as well as their implantation into femoral bone defects, showed very promising osteogenic potential. ${ }^{85}$ Porous $\beta$-TCP/COLI composite scaffolds wrapped in BMSC sheets after osteogenic induction implanted in nude mice have also shown superior osteogenic ability. ${ }^{86}$ BMSC sheets from both young and old rats after osteogenic induction were combined with $\beta$-TCP scaffolds and transplanted subcutaneously into recipient rats; bone formation was promoted in both the young and old BMSC sheets groups, indicating that BMSC sheets from old donors were also capable of bone regeneration. ${ }^{87}$ In addition to the most widely used $\beta$-TCP ceramic scaffold, polymeric scaffolds, including poly (sebacoyl diglyceride) (PSeD) and poly(lactic-co-glycolic acid) (PLGA), combined with cell sheets have also been studied for bone regeneration. Xie et al. wrapped human ethmoid sinus mucosal membrane-derived MSC sheets around porous PSeD scaffolds pre-seeded with rat BMSCs and showed that implantation of these constructs into 8-mm-diameter critical-sized calvarial defects in rats promoted new bone regeneration. ${ }^{21}$ The utilisation of PLGA scaffolds wrapped in BMSC sheets after osteogenic induction also improved bone regeneration in canine mandibular bone defects. ${ }^{88}$ Furthermore, scaffolds derived from natural bone, including calcined bovine bones and allografts, have been studied. Liu et al. wrapped rat BMSCs after osteogenic induction around calcined bovine bones (CBBs) to form CBB-BMSC sheet constructs. Upon implantation of these constructs into $8-\mathrm{mm}^{-}$ diameter critical-sized calvarial bone defects in osteoporotic rats, the BMSC sheets survived in the scaffold and participated in new bone formation. ${ }^{89}$ Devitalised allografts wrapped in mouse BMSC sheets were transplanted into 4-mm critical-sized murine femoral segmental bone defects by Long et al., who showed that the BMSC sheets improved bone callus formation during allograft healing in bone defects and enhanced allograft osseointegration. ${ }^{90}$

Growth factors play a key role in tissue regeneration due to their excellent regenerative potential in various tissues, such as bone and cartilage. ${ }^{91}$ Recently, growth factors have been utilised with cell sheets to promote bone regeneration. The platelet-rich plasma (PRP) gel contains several growth factors, including platelet-derived growth factor (PDGF), transforming growth factor (TGF- $\beta 1$, TGF- $\beta 2$ ), insulin-like growth factor (IGF-1, IGF-2) and vascular endothelial growth factor. Qi et al. combined rat BMSC sheets prepared by the mechanical system with the PRP gel and $\mathrm{CaP}$ particles and then transplanted the constructs into cortical bone defects in rat femurs. They discovered that incorporating 


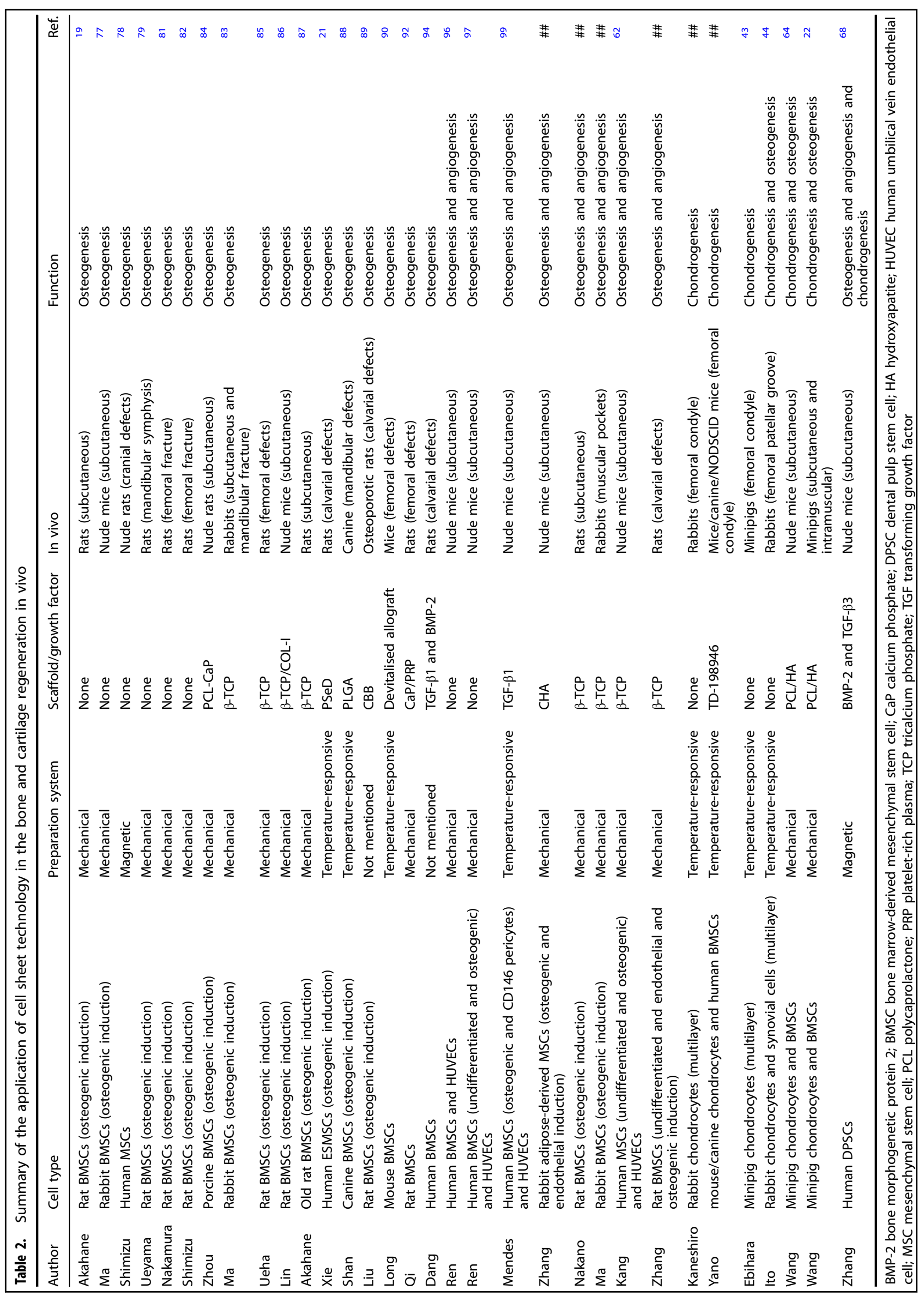


PRP gel/CaP particles into BMSC sheets enhanced bone regeneration. ${ }^{92}$ Unlike the intramembranous ossification-based bone tissue engineering strategy, which mimics the embryological process and requires the immediate establishment of initial vascular networks for implant survival, the endochondral ossification-based bone tissue engineering strategy utilises engineered cartilage as a transient template that can survive in an avascular environment and is capable of inducing angiogenesis via hypertrophic chondrocytes to promote bone regeneration and fracture healing. ${ }^{93}$ Bioactive microparticles capable of not only the controlled delivery of TGF- $\beta 1$ early to induce cartilage formation but also the sustained delivery of bone morphogenetic protein 2 (BMP-2) to promote bone remodelling were engineered by Dang et al. Human BMSC sheets combined with such microparticles containing growth factors were implanted into rat critical-sized calvarial bone defects and were shown to accelerate bone defect healing. ${ }^{94}$

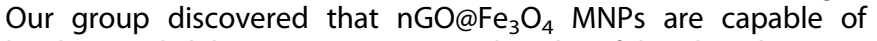
binding and delivering proteins via the plentiful carboxyl groups provided by the nGO coating (Fig. 3a). The ability of nGO@Fe $\mathrm{O}_{4}$ MNPs to bind proteins was verified by incubation with phycoerythrin-labelled secondary antibody (2Ab-PE) and different concentrations of bovine serum albumin (Fig. 3b, C). We were able to utilise $\mathrm{nGO} @ \mathrm{Fe}_{3} \mathrm{O}_{4}$ MNPs to bind BMP-2 in a concentrationdependent manner (Fig. 3d). Novel scaffold-free osteogenic microtissues comprising cell sheets with immobilised growth factor were constructed by attracting nGO@ $\mathrm{Fe}_{3} \mathrm{O}_{4}$ MNP-labelled DPSCs and nGO@ $\mathrm{Fe}_{3} \mathrm{O}_{4}$ MNP-bound BMP-2 with magnetic force. Upon subcutaneous implantation of BMP-2-loaded DPSC sheets into nude mice, host blood vessels grew into the microtissue, new bone formed around the microtissue and the nGO@Fe $\mathrm{O}_{4} \mathrm{MNP}$ labelled DPSCs differentiated into osteoblasts (Fig. 3e, f). ${ }^{68}$

Vascularisation is essential for the repair of large bone defects. Recently, strategies consisting of co-culturing cell sheets with vascular endothelial cells, stacking vascular endothelial cell sheets with other types of cell sheets or even inserting vascular bundles in cell sheet scaffold constructs have been utilised to construct cell sheets capable of promoting vascularised bone regeneration. Mechanical or temperature-responsive systems were used to prepare the cell sheets. Asakawa et al. created three-dimensional (3D) stratified tissues by stacking cell sheets with HUVEC sheets a
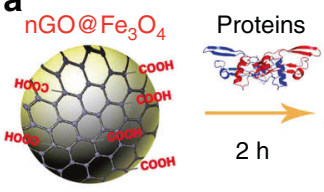

b
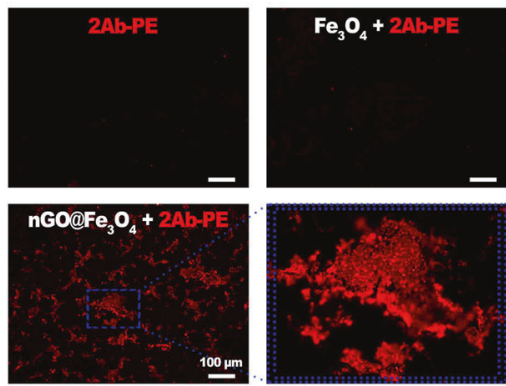

C $\mathrm{nGO} @ \mathrm{Fe}_{3} \mathrm{O}_{4} \quad \mathrm{Fe}_{3} \mathrm{O}_{4}$

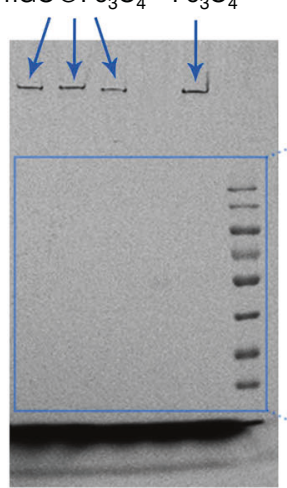

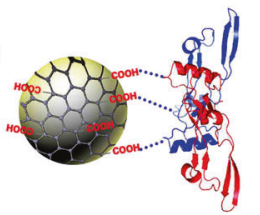
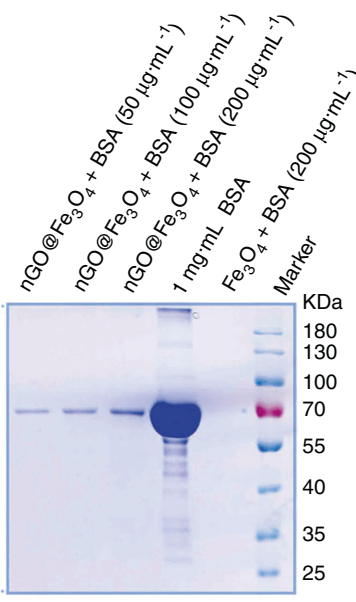

Coomassie blue staining d
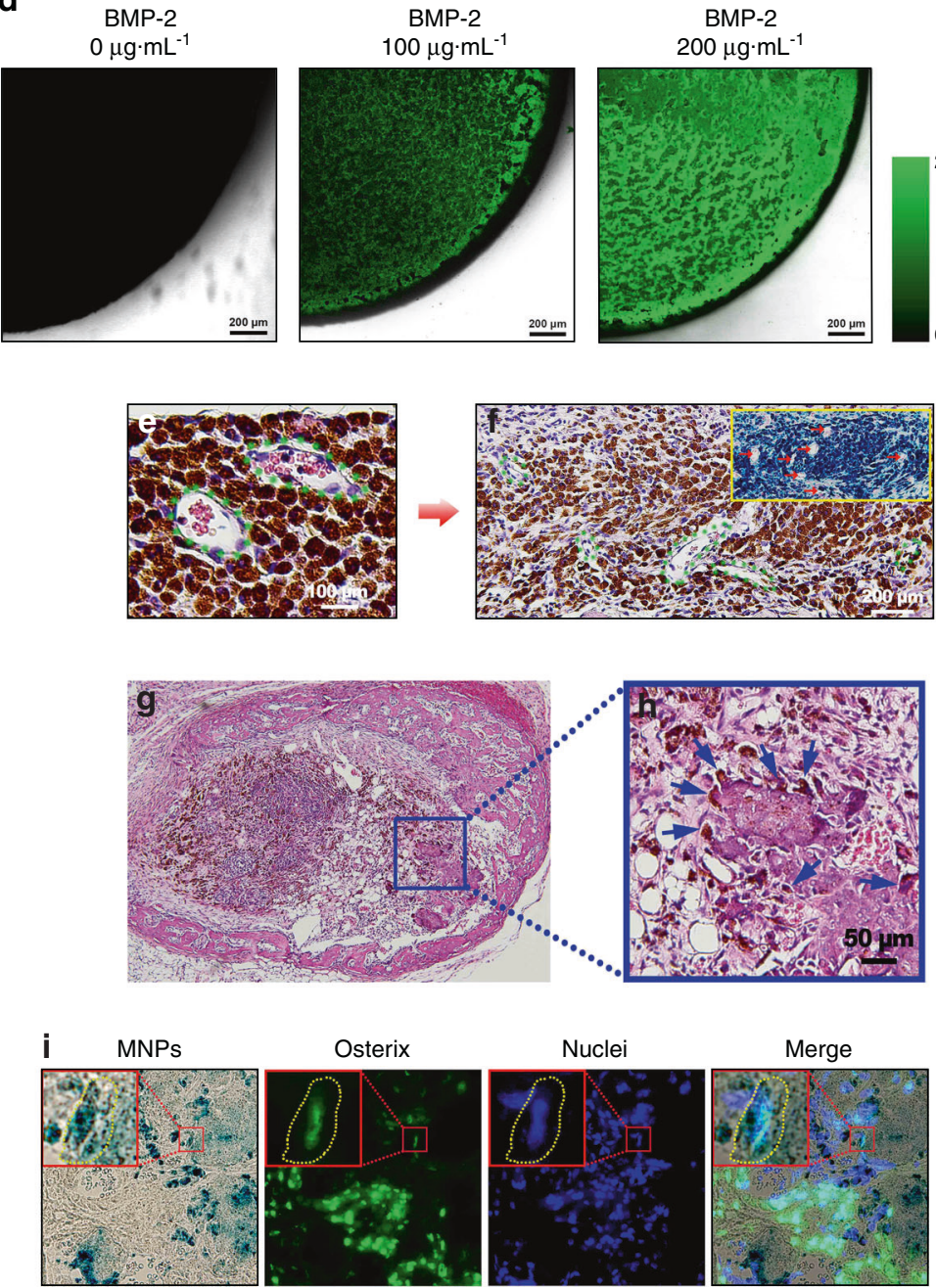

Fig. 3 The construction and application of osteogenic microtissues comprising growth-factor-immobilised cell sheets via magnetic force.

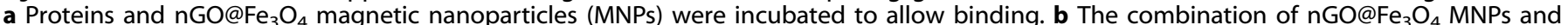
$2 \mathrm{Ab}$-PE was detected. $\mathbf{c}$ The binding ability of $\mathrm{nGO} @ \mathrm{Fe}_{3} \mathrm{O}_{4} \mathrm{MNPs}$ and bovine serum albumin at different concentrations was assessed. $\mathbf{d}$ The binding of $\mathrm{nGO} @ \mathrm{Fe}_{3} \mathrm{O}_{4}$ MNPs and bone morphogenetic protein 2 (BMP-2) at different concentrations was detected. e The blood vessels were observed to grow into the dental pulp stem cell (DPSC) sheet after subcutaneous implantation in nude mice for 1 week. $\mathbf{f}$ After implantation for 1 month, blood vessels were observed, and the larger vessels were labelled. $\mathbf{g}$ After implantation for 1 month, new bone formation was observed around the BMP-2-immobilised cell sheets. $\mathbf{h}$ The labelled cells were observed to migrate to and participate in the newly formed bone. i The nGO@Fe $\mathrm{O}_{4}$ MNP-labelled DPSCs were directly observed to differentiate into osteoblasts. (Adapted from ref. ${ }^{68}$ with permission.) 
and discovered that pre-vascular networks composed of HUVECs formed tubular structures, similar to those of native microvasculature in vitro. ${ }^{95}$ Ren et al. created a highly pre-vascularised 3D cell sheet construct by seeding HUVECs on human BMSC sheets and then folding the sheets into a 3D structure. Subcutaneous implantation of the constructs into immunodeficient mice revealed that the pre-vascularised constructs promoted blood vessel formation and functional anastomosis with the host vasculature. ${ }^{96}$ This research group further created a composite construct consisting of an inner highly pre-vascularised cell sheet, which was formed by seeding HUVECs on undifferentiated human BMSC sheets, and an outer osteogenic layer, which was formed by human BMSCs after osteogenic induction. The undifferentiated human BMSC sheets improved the alignment of HUVECs in vitro and promoted the formation of vascular-like networks; in addition, the seeded HUVECs rearranged the ECM secreted by human BMSCs. Subcutaneous implantation of the composite constructs into nude mice resulted in rapid vascularisation and anastomosis with the host vasculature, as well as the formation of functional blood vessels. ${ }^{97}$ Pericytes located within the basement membrane of capillaries and postcapillary venules have a great impact on blood vessel wall stabilisation, endothelial cell proliferation and migration and microvascular blood flow regulation. ${ }^{98} \mathrm{~A}$ scaffoldfree construct was created by combining human BMSC sheets after osteogenic induction with HUVECs and perivascular-like $(C D 146+)$ cells, which were induced from human BMSCs. Subcutaneous implantation of the construct into nude mice revealed its excellent osteogenic and angiogenic potential. ${ }^{99} \mathrm{~A}$ double cell sheet complex was formed by combining an osteogenic cell sheet with a vascular endothelial cell sheet, with both sets of cells induced from rabbit adipose-derived MSCs. Subcutaneous implantation of this complex into nude mice showed that it had an excellent ability to promote osteogenesis and angiogenesis. In addition, the combination of the double cell sheet complex with a coral hydroxyapatite (HA) scaffold resulted in the synergistic promotion of both osteogenesis and blood vessel formation. ${ }^{100} \mathrm{~A}$ novel vascularised tissue-engineered bone scaffold was developed by wrapping osteogenic matrix cell sheets induced from rat BMSCs around a microporous $\beta$-TCP scaffold with a side groove. Subcutaneous implantation of the sheet scaffold constructs into rats with femoral vascular bundles passing through the groove promoted vascularisation and new bone formation. ${ }^{101}$ Another study used an arteriovenous loop (AVL) to circle a $\beta$-TCP scaffold by insertion into the lateral groove. Then the construct was wrapped in a rabbit BMSC sheet and transplanted into the thigh muscle pockets of rabbits. New bone formation and vascularisation were promoted by the combination of a BMSC sheet, $\beta$-TCP scaffold and AVL. ${ }^{102}$

The periosteum is a thin membrane that covers the outer surface of bones and plays a significant role in bone development and regeneration. The periosteum is mainly composed of an outer fibrous layer that contains fibroblasts, collagen fibres and blood vessels and nourishes the inner bone and an inner osteogenic layer that contains MSCs and osteoprogenitor cells and is responsible for bone development and regeneration. ${ }^{103}$ Multilayered cell sheets have been prepared using mechanical systems to promote vascularised bone regeneration by mimicking the native periosteum structure. Kang et al. seeded HUVECs on undifferentiated human MSC sheets to mimic the fibrous layer of native periosteum, while an osteogenic human MSC sheet was cultured to mimic the osteogenic layer of native periosteum. Combining these two cell sheets and wrapping them around a $\beta$-TCP scaffold resulted in a biomimetic, cell sheet-based engineered periosteum. Subcutaneous implantation of the cell sheet scaffold construct into nude mice enhanced angiogenesis, functional anastomosis with the host vasculature and osteogenesis (Fig. 4). ${ }^{62}$ Zhang et al. combined undifferentiated rat BMSCs with induced endothelial-like cells differentiated from rat BMSCs to form a pre-vascularised cell sheet mimicking the fibrous layer of native periosteum. An osteogenic cell sheet differentiated from rat BMSCs mimicking the osteogenic layer of native periosteum was wrapped within the pre-vascularised cell sheet to form a biomimetic periosteum. Then a porous $\beta$-TCP scaffold was wrapped within the biomimetic periosteum and transplanted into rat calvarial defects, wherein the scaffold promoted the formation of blood vessels and new bone tissue. ${ }^{104}$

Progress in the application of cell sheet technology in articular cartilage and bone-cartilage complex regeneration

Articular cartilage is a highly organised, resilient connective tissue that covers the surface of bone. ${ }^{105}$ Owing to the lack of a blood supply and the low density of chondrocytes, self-repair of articular cartilage is difficult once the latter is damaged. ${ }^{2}$ In recent years, cell sheet technology has shown great potential for cartilage regeneration. ${ }^{106}$ Compared with monolayers, multilayered chondrocyte sheets showed high expression levels of chondrogenicrelated genes and proteins, as well as of cell adhesion-related genes and proteins, indicating that multilayered chondrocyte sheets closely mimic native cartilage and might have great ability to regenerate cartilage. ${ }^{107}$ Moreover, multilayered chondrocyte sheets were able to secrete high levels of humoural factors, such as TGF- $\beta$ and prostaglandin E2, which play key roles in cartilage regeneration. ${ }^{108}$ Multilayered rabbit chondrocyte sheets were prepared by the temperature-responsive system and transplanted into partial-thickness cartilage defects in rabbit femoral condyles at a depth of $<1 \mathrm{~mm}$. The multilayered chondrocyte sheets were capable of maintaining the cartilage phenotype and both attaching to and covering the cartilage defects to protect proteoglycans from catabolic factors in the joint. ${ }^{109}$ Yano et al. identified a novel small thienoindazole derivative, TD-198946, by screening 2500 natural and synthetic small compounds for cartilage regeneration. TD-198946 was able to induce chondrogenic differentiation and abundant ECM production while simultaneously suppressing hypertrophic differentiation and endochondral ossification; therefore, regenerated cartilage could be maintained without being replaced by bone. ${ }^{110}$ By using the temperature-responsive system, multilayered chondrocyte sheets were created using mouse chondrocytes or canine costal dedifferentiated chondrocytes and human BMSC sheets treated with TD-198946 and then transplanted into defects in the femoral condylar cartilage of mice (1 $\mathrm{mm}$ in diameter), canines $(3 \mathrm{~mm}$ in diameter and $1 \mathrm{~mm}$ in depth) and NOD/SCID mice $(1 \mathrm{~mm}$ in diameter). The transplanted cell sheets promoted cartilage regeneration without causing chondrocyte hypertrophy. ${ }^{43}$

In addition to the destruction of articular cartilage, the destruction of subchondral bone is usually involved in osteoarthritis. ${ }^{111}$ Therefore, the repair of bone-cartilage complex defects has received much attention in the field of regenerative medicine, and many researchers have applied the cell sheet technology for the treatment of bone-cartilage complex defects. Multilayered chondrocyte sheets prepared by the temperature-responsive system were autologously transplanted into full-thickness femoral condylar cartilage defects $6 \mathrm{~mm}$ in diameter and $5 \mathrm{~mm}$ in depth in minipigs by Ebihara et al., who discovered that the multilayered chondrocyte sheets promoted cartilage repair and regeneration. However, in some cases, the effect on subchondral bone regeneration was unsatisfactory. ${ }^{20}$ Multilayered chondrocyte sheets combined with synovial cells using the temperatureresponsive system were transplanted into osteochondral defects $5 \mathrm{~mm}$ in diameter and $3 \mathrm{~mm}$ in depth in the femoral patellar groove of rabbits by lto et al., who reported increased repair and regeneration of both cartilage and subchondral bone in bone-cartilage complex defects. ${ }^{44}$ Wang et al. utilised minipigderived chondrocyte sheets prepared by the mechanical system to cover PCL/HA scaffolds seeded with minipig-derived BMSCs. Subcutaneous implantation of the constructs into nude mice 
a

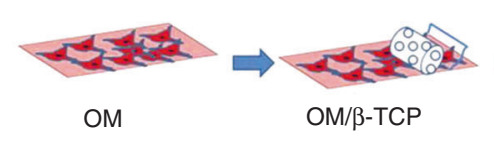

OM

$\mathrm{OM} / \beta-\mathrm{TCP}$

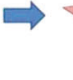

HUVEC-UM

Group 1

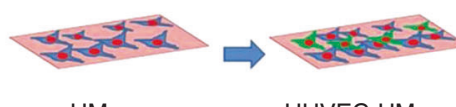

UM

HUVEC-UM

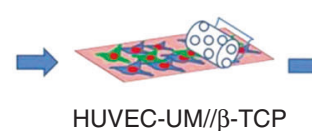

HUVEC-UM// $\beta-T C P$

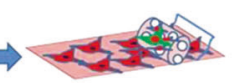

OM/HUVEC-UM/ $\beta$-TCP

Group 2

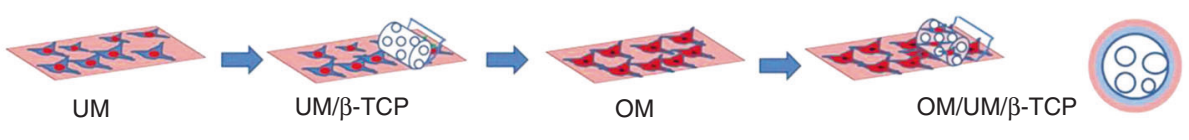

Group 3

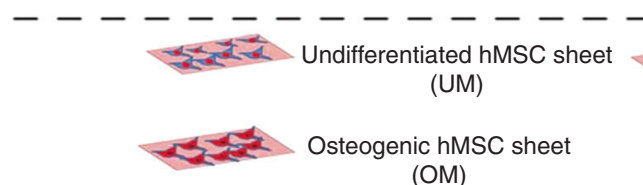

(OM)

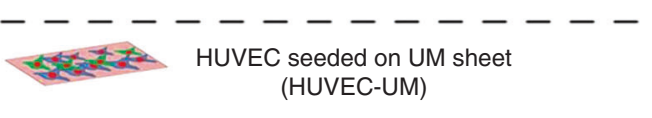

(HUVEC-UM)

Porous $\beta$-TCP scaffold

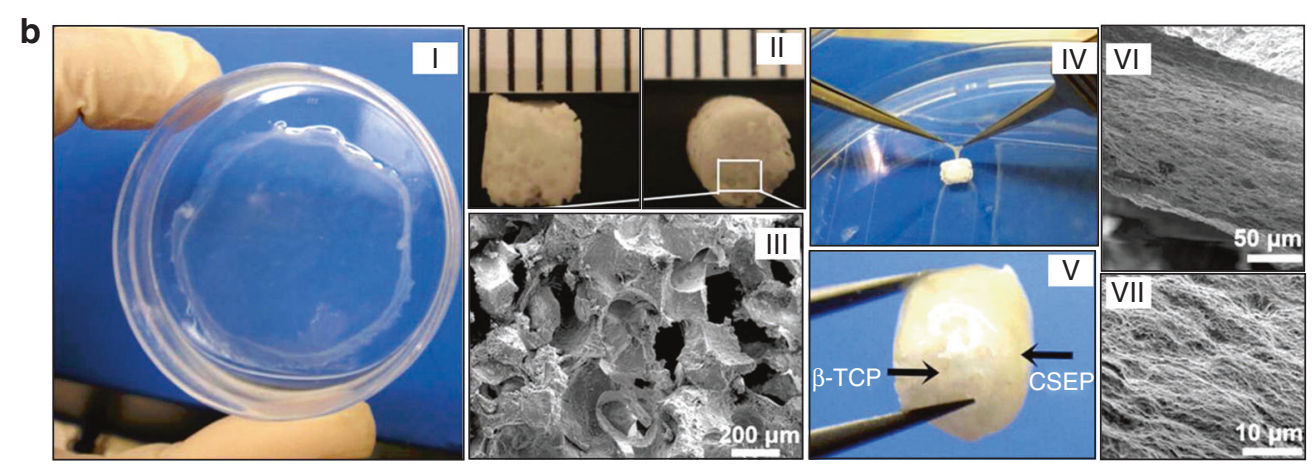

Fig. 4 Procedures for preparing cell sheet/beta tricalcium phosphate $(\beta$-TCP) composite grafts. a Preparing three cell sheet/ $\beta$-TCP grafts including OM/UM/ $\beta-T C P, O M / H U V E C-U M / \beta-T C P$, and HUVEC-UM/OM/ $\beta$-TCP. b Macroscopic view of an human mesenchymal stem cell sheet on a dish (I) and a porous $\beta$-TCP scaffold (II). The scanning electron microscopic (SEM) image demonstrates the morphology of $\beta$-TCP pores (III). Point forceps were used to wrap the cell sheet onto a $\beta$-TCP scaffold (IV), thus generating a HUVEC-UM/OM/ $\beta$-TCP graft (V). The SEM images show a very dense extracellular matrix of cell sheets on a $\beta$-TCP scaffold (VI, VII). (Adapted from ref. ${ }^{62}$ with permission. Further permissions related to the material excerpted should be directed to the ACS: https://pubs.acs.org.ccindex.cn/doi/10.1021/am502056q.)

regenerated condyle-shaped osteochondral composites. ${ }^{64}$ In addition to immunodeficient animal models, minipigs have been used to show that subcutaneous and intramuscular construct transplantation results in the regeneration of biological condyles with an osteochondral construction similar to that of native condyles. ${ }^{22}$ Takaku et al. used the temperature-responsive system to prepare multilayered cell sheets consisting of both chondrocytes and synovial cells from firefly luciferase-expressing transgenic rats and transplanted them into wild-type rats. The transplanted cell sheets could remain and survive in osteochondral defects in the knee joint for up to 21 months, which confirmed the effects of the cell sheets on the repair and regeneration of bone-cartilage complex defects. ${ }^{112}$ The mechanism of cell sheet-mediated repair of bone-cartilage complex defects was discovered by Shimizu et al. via cell tracking experiments using green fluorescent protein (GFP) transgenic rats. Moreover, these researchers found that higher expression of TGF- $\beta 1$ in chondrocyte sheets might contribute to cartilage repair. ${ }^{13}$

Our group constructed microtissues consisting of chondrogenic cell sheets and osteogenic cell sheets for the repair of bone-cartilage complex defects based on the magnetically controlled approach. The osteogenic growth factor BMP-2 and the chondrogenic growth factor TGF- $\beta 3$ were bound to nGO@$\mathrm{Fe}_{3} \mathrm{O}_{4}$ MNPs. Magnetically attracting nGO@ $\mathrm{Fe}_{3} \mathrm{O}_{4}$ MNP-labelled DPSCs and $\mathrm{nGO@Fe} \mathrm{O}_{3}$ MNP-bound growth factors led to the creation of microtissues with a closely integrated double-layered structure mimicking the cartilage-bone interface (Fig. 5a), in which the upper layer was DPSC sheets with immobilised TGF- $\beta 3$ and the lower layer was DPSC sheets with immobilised BMP-2 (Fig. 5b). One week after the subcutaneous implantation of these microtissues into nude mice, DPSCs in the upper and lower layers were observed to have differentiated into mCherry+ chondrocytes and GFP + osteoblasts, respectively (Fig. 5c, d). ${ }^{68}$

\section{CHALLENGES IN APPLYING THE CELL SHEET TECHNOLOGY IN BONE AND CARTILAGE REGENERATION AND POTENTIAL RESEARCH AREAS}

In recent decades, much progress has been made in the preparation and application of cell sheets. With the efforts of many researchers, cell sheet technology is becoming a promising strategy for the repair and regeneration of bone and cartilage defects. However, some obstacles remain in the application of cell sheet technology. For example, constructing tissue or organ-like tissue with a complicated structure and morphology is difficult, 

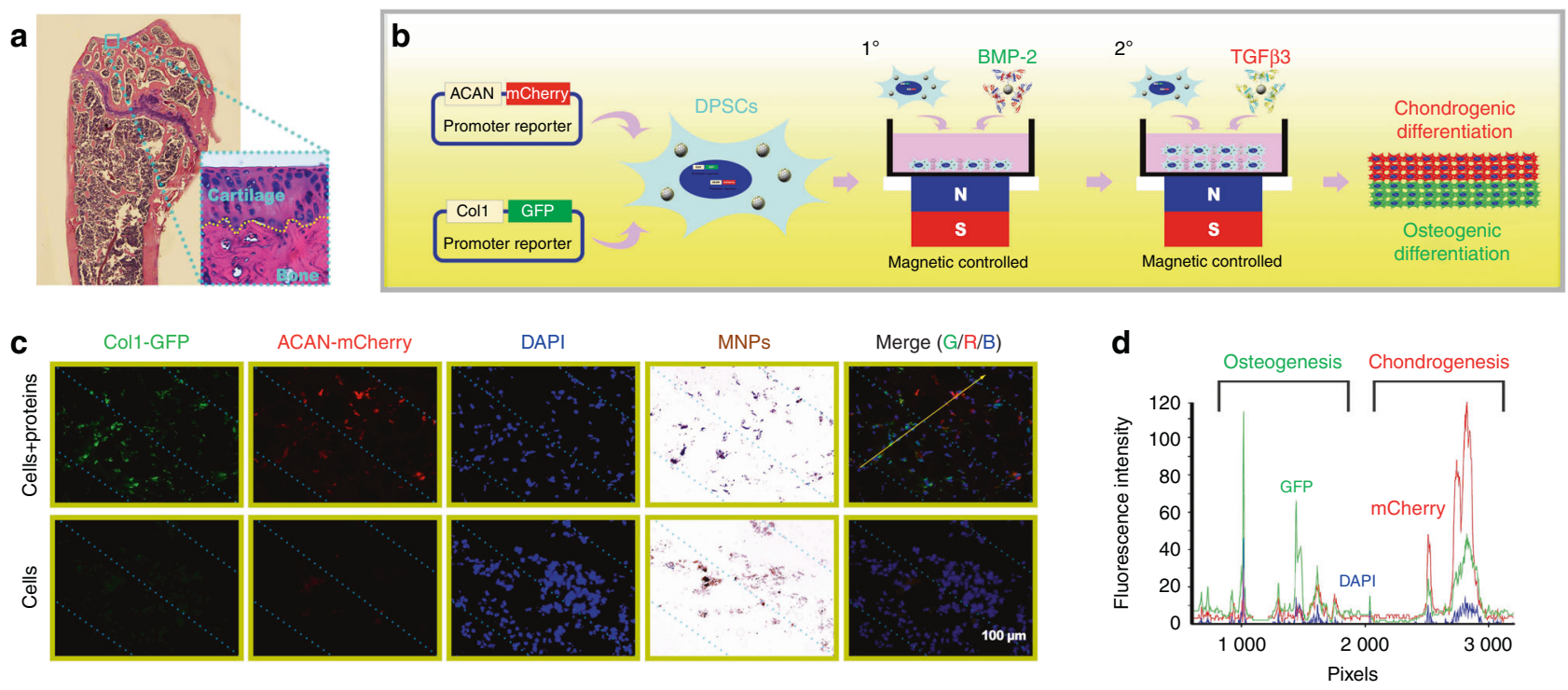

Fig. 5 The construction and application of osteochondral microtissues composed of chondrogenic cell sheets and osteogenic cell sheets based on the magnetically controlled approach. a The structure of the normal mouse knee joint with the cartilage-bone interface labelled by a yellow dotted line. b Schematic illustration of the process used to construct an integrated osteochondral tissue via the magnetically controlled method. c After implantation for 1 week, mCherry+ chondrocytes and GFP+ osteoblasts were observed using a fluorescence microscope. $\mathbf{d}$ The fluorescence intensity along the yellow arrow was recorded. (Adapted from ref. ${ }^{68}$ with permission.)

and the constructed cell sheets usually lack mechanical properties. The cells in multilayered cell sheets are prone to necrosis. In addition, the components of cells and ECM in cell sheets are quite different from those in native cartilage.

To construct 3D bone and cartilage, the cells or cell sheets must be stacked to form complex structures and shapes. Various systems are available for constructing cell sheets. Temperatureresponsive and mechanical approaches are the most widely used to prepare cell sheets for bone and cartilage regeneration, likely because temperature-responsive systems are the most traditional and widely studied systems and because mechanical approaches are easy due to the lack of a need for specific culture substrates or techniques. The stacking technique is widely utilised for the preparation of multilayered cell sheets. With the application of magnetic technology, multilayered cell sheets can be prepared by magnetically attracting MNP-labelled cells layer by layer in a single step. Cell patterning and micropatterning technology has been introduced to modify the morphology of cell sheets. In a magnetic system, the shape of cell sheets can be precisely controlled using different numbers of magnets or magnet patterns. However, using existing cell sheet preparation techniques to prepare relatively more complex tissues and even organs is still challenging. Thus existing preparation systems need to be further improved, or novel effective preparation systems need to be proposed.

The maintenance of a sufficient nutrient and oxygen supply and the efficient exchange of cellular metabolites contribute to the survival of cells in cell sheets. Cells deep in thick multilayered cell sheets are prone to necrosis during application for bone tissue regeneration due to the insufficient nutrient and oxygen supply and the poor exchange of cell waste. Vascularisation is of great importance for bone tissue regeneration. The rapid growth of blood vessels into transplanted cell sheets can supply nutrients and oxygen and exchange metabolites in a timely manner, thus effectively promoting the survival of transplanted cells and the growth of host tissues. The rapid vascularisation of cell sheets is an important research direction for bone regeneration.

Native cartilage is composed of a large amount of ECM components and a small number of chondrocytes. However, currently prepared cell sheets usually contain a large number of cells with a relatively small proportion of ECM and are quite different from native cartilage. Recently, a micropatterned collagen sheet was fabricated by the permeation of a piece of doughnut-shaped paper by a cell-collagen mixture, and the components of this sheet are more similar to native cartilage than the other cell sheets mentioned above. ${ }^{114}$ Constructing cell sheets with a composition similar to that of native cartilage is crucial; however, further research is needed for the application of such sheets in cartilage regeneration.

\section{ACKNOWLEDGEMENTS}

This work was jointly supported by the National Key Research and Development Program of China (2016YFC1102900) and the National Natural Science Foundation of China (No.81620108006, No.81430012, and No.31700848).

\section{ADDITIONAL INFORMATION}

The online version of this article (https://doi.org/10.1038/s41368-019-0050-5) contains supplementary material, which is available to authorized users.

Competing interests: The authors declare no competing interests.

\section{REFERENCES}

1. Grayson, W. L. et al. Stromal cells and stem cells in clinical bone regeneration. Nat. Rev. Endocrinol. 11, 140-150 (2015).

2. Makris, E. A., Gomoll, A. H., Malizos, K. N., Hu, J. C. \& Athanasiou, K. A. Repair and tissue engineering techniques for articular cartilage. Nat. Rev. Rheumatol. 11, 21-34 (2015).

3. Li, G., Zhou, T., Lin, S., Shi, S. \& Lin, Y. Nanomaterials for craniofacial and dental tissue engineering. J. Dent. Res. 96, 725 (2017).

4. Jazayeri, H. E. et al. A current overview of materials and strategies for potential use in maxillofacial tissue regeneration. Mater. Sci. Eng. C Mater. Biol. Appl. 70, 913-929 (2017).

5. Daly, A. C. et al. 3D bioprinting for cartilage and osteochondral. Tissue Eng. Adv. Healthc. Mater. 6, 1700298 (2017).

6. Liu, M. et al. Injectable hydrogels for cartilage and bone tissue engineering. Bone Res. 5, 75-94 (2017) 
7. Hutmacher, D. W. Scaffolds in tissue engineering bone and cartilage. Biomaterials 21, 2529-2543 (2000).

8. Gao, C., Peng, S., Feng, P. \& Shuai, C. Bone biomaterials and interactions with stem cells. Bone Res. 5, 17059 (2017).

9. Yang, J. et al. Cell sheet engineering: recreating tissues without biodegradable scaffolds. Biomaterials 26, 6415-6422 (2005).

10. Takezawa, T., Mori, Y. \& Yoshizato, K. Cell culture on a thermo-responsive polymer surface. Nat. Biotechnol. 8, 854-856 (1990).

11. Yamada, N. et al. Thermo-responsive polymeric surfaces; control of attachment and detachment of cultured cells. Makromol. Chem. Rapid Commun. 11, 571-576 (1990).

12. Yamato, M. et al. Temperature-responsive cell culture surfaces for regenerative medicine with cell sheet engineering. Prog. Polym. Sci. 32, 1123-1133 (2007).

13. Matsuda, N., Shimizu, T., Yamato, M. \& Okano, T. Tissue engineering based on cell sheet technology. Adv. Mater. 19, 3089-3099 (2007).

14. Shuilin, W. U. et al. Biomimetic porous scaffolds for bone tissue engineering. Mat. Sci. Eng. R. 80, 1-36 (2014).

15. Roseti, L. et al. Scaffolds for bone tissue engineering: state of the art and new perspectives. Mater. Sci. Eng. C Mater. Biol. Appl. 78, 1246-1262 (2017).

16. Kawecki, F., Clafshenkel, W. P., Fortin, M., Auger, F. A. \& Fradette, J. Biomimetic tissue-engineered bone substitutes for maxillofacial and craniofacial repair: the potential of cell sheet technologies. Adv. Healthc. Mater. 7, e1700919 (2017).

17. Yorukoglu, A. C., Kiter, A. E., Akkaya, S., Satiroglu-Tufan, N. L. \& Tufan, A. C. A concise review on the use of mesenchymal stem cells in cell sheet-based tissue engineering with special emphasis on bone tissue regeneration. Stem Cells Int. 2017, 2374161 (2017).

18. Li, M., Ma, J., Gao, Y. \& Yang, L. Cell sheet technology: a promising strategy in regenerative medicine. Cytotherapy 21, 3-16 (2019).

19. Akahane, M. et al. Osteogenic matrix sheet-cell transplantation using osteoblastic cell sheet resulted in bone formation without scaffold at an ectopic site. J. Tissue Eng. Regen. Med. 2, 196-201 (2008).

20. Ebihara, G. et al. Cartilage repair in transplanted scaffold-free chondrocyte sheets using a minipig model. Biomaterials 33, 3846-3851 (2012).

21. Xie, Q. et al. Characterization of human ethmoid sinus mucosa derived mesenchymal stem cells (hESMSCs) and the application of hESMSCs cell sheets in bone regeneration. Biomaterials 66, 67-82 (2015).

22. Wang, F., Hu, Y., He, D., Zhou, G. \& Ellis, I. I. I. E. Scaffold-free cartilage cell sheet combined with bone-phase BMSCs-scaffold regenerate osteochondral construct in mini-pig model. Am. J. Transl. Res. 10, 2997 (2018).

23. Patel, N. G. \& Zhang, G. Responsive systems for cell sheet detachment. Organogenesis 9, 93-100 (2013).

24. Silva, R. M. P. D., Mano, J. F. \& Reis, R. L. Smart thermoresponsive coatings and surfaces for tissue engineering: switching cell-material boundaries. Trends Biotechnol. 25, 577-583 (2007).

25. Kumashiro, Y., Yamato, M. \& Okano, T. Cell attachment-detachment control on temperature-responsive thin surfaces for novel tissue engineering. Ann. Biomed. Eng. 38, 1977-1988 (2010).

26. Tang, Z. \& Okano, T. Recent development of temperature-responsive surfaces and their application for cell sheet engineering. Regen. Biomater. 1, 91 (2014).

27. Hatakeyama, H., Kikuchi, A., Yamato, M. \& Okano, T. Influence of insulin immobilization to thermoresponsive culture surfaces on cell proliferation and thermally induced cell detachment. Biomaterials 26, 5167-5176 (2005).

28. Ebara, M., Yamato, M. T., Kikuchi, A., Sakai, K. \& Okano, T. Immobilization of celladhesive peptides to temperature-responsive surfaces facilitates both serumfree cell adhesion and noninvasive cell harvest. Tissue Eng. 10, 1125-1135 (2004).

29. Kwon, O. H., Kikuchi, A., Yamato, M., Sakurai, Y. \& Okano, T. Rapid cell sheet detachment from poly(N-isopropylacrylamide)-grafted porous cell culture membranes. J. Biomed. Mater. Res. B 50, 82-89 (2000).

30. Kwon, O. H., Kikuchi, A., Yamato, M. \& Okano, T. Accelerated cell sheet recovery by co-grafting of PEG with PIPAAm onto porous cell culture membranes. Biomaterials 24, 1223-1232 (2003).

31. Ebara, M. et al. Copolymerization of 2-carboxyisopropylacrylamide with $\mathrm{N}$ isopropylacrylamide accelerates cell detachment from grafted surfaces by reducing temperature. Biomacromolecules 4, 344-349 (2003).

32. Guo, B. et al. Saccharides and temperature dual-responsive hydrogel layers for harvesting cell sheets. Chem. Commun. (Camb.) 51, 644-647 (2014).

33. Patel, N. G., Cavicchia, J. P., Ge, Z. \& Newby, B. M. Z. Rapid cell sheet detachment using spin-coated pNIPAAm films retained on surfaces by an aminopropyltriethoxysilane network. Acta Biomater. 8, 2559-2567 (2012).

34. Hannachi, I. E., Yamato, M. \& Okano, T. Cell sheet technology and cell patterning for biofabrication. Biofabrication 1, 022002 (2009).

35. Guillotin, B. \& Guillemot, F. Cell patterning technologies for organotypic tissue fabrication. Trends Biotechnol. 29, 183-190 (2011).
36. Hatakeyama, H., Kikuchi, A., Yamato, M. \& Okano, T. Patterned biofunctional designs of thermoresponsive surfaces for spatiotemporally controlled cell adhesion, growth, and thermally induced detachment. Biomaterials 28, 3632-3643 (2007).

37. Tsuda, Y. et al. The use of patterned dual thermoresponsive surfaces for the collective recovery as co-cultured cell sheets. Biomaterials 26, 1885-1893 (2005).

38. Isenberg, B. C. et al. A thermoresponsive, microtextured substrate for cell sheet engineering with defined structural organization. Biomaterials 29, 2565-2572 (2008).

39. Isenberg, B. C. et al. Micropatterned cell sheets with defined cell and extracellular matrix orientation exhibit anisotropic mechanical properties. J. Biomech. 45, 756-761 (2012).

40. Lin, J. B. et al. Thermo-responsive poly( $\mathrm{N}$-isopropylacrylamide) grafted onto microtextured poly(dimethylsiloxane) for aligned cell sheet engineering. Colloid Surf. B 99, 108-115 (2012).

41. Williams, C. et al. Aligned cell sheets grown on thermo-responsive substrates with microcontact printed protein patterns. Adv. Mater. 21, 2161-2164 (2009).

42. Hannachi, I. E. et al. Fabrication of transferable micropatterned-co-cultured cell sheets with microcontact printing. Biomaterials 30, 5427-5432 (2009).

43. Yano, F. et al. Cell-sheet technology combined with a thienoindazole derivative small compound TD-198946 for cartilage regeneration. Biomaterials 34, 5581-5587 (2013).

44. Ito, S. et al. Repair of articular cartilage defect with layered chondrocyte sheets and cultured synovial cells. Biomaterials 33, 5278-5286 (2012).

45. Guillaume-Gentil, O. et al. Polyelectrolyte coatings with a potential for electronic control and cell sheet engineering. Adv. Mater. 20, 560-565 (2008).

46. Inaba, R., Khademhosseini, A., Suzuki, H. \& Fukuda, J. Electrochemical desorption of self-assembled monolayers for engineering cellular tissues. Biomaterials $\mathbf{3 0}$, 3573-3579 (2009).

47. Seto, Y. et al. Engineering of capillary-like structures in tissue constructs by electrochemical detachment of cells. Biomaterials 31, 2209-2215 (2010).

48. Mochizuki, N. et al. Tissue engineering based on electrochemical desorption of an RGD-containing oligopeptide. J. Tissue Eng. Regen. Med. 7, 236-243 (2013).

49. Kakegawa, T., Mochizuki, N., Sadr, N., Suzuki, H. \& Fukuda, J. Cell-adhesive and cell-repulsive zwitterionic oligopeptides for micropatterning and rapid electrochemical detachment of cells. Tissue Eng. A 19, 290-298 (2013).

50. Guillaume-Gentil, O., Gabi, M., Zenobi-Wong, M. \& Vörös, J. Electrochemically switchable platform for the micro-patterning and release of heterotypic cell sheets. Biomed. Microdevices 13, 221-230 (2011).

51. Enomoto, J. et al. Engineering thick cell sheets by electrochemical desorption of oligopeptides on membrane substrates. Regen. Ther. 3, 24-31 (2016).

52. Guillame-Gentil, O. et al. Engineering the extracellular environment: strategies for building 2D and 3D cellular structures. Adv. Mater. 22, 5443-5462 (2010).

53. Hong, Y. et al. Light-induced cell detachment for cell sheet technology. Biomaterials 34, 11-18 (2013).

54. Zhu, Y., Cheng, Z., Weng, W., Cheng, K. J. C. \& Biointerfaces, S. B. A facile synthesis of polydopamine/TiO2 composite films for cell sheet harvest application. Colloid Surf. B 172, 355-361 (2018).

55. $\mathrm{Yu}, \mathrm{M}$. L. et al. The effects of $\mathrm{TiO}_{2}$ nanodot films with RGD immobilization on light-induced cell sheet technology. Biomed. Res. Int. 2015, 582359 (2015).

56. Cheng, K. et al. Effects of RGD immobilization on light-induced cell sheet detachment from TiO2 nanodots films. Mater. Sci. Eng. C Mater. Biol. Appl. 63, 240-246 (2016).

57. Jiang, Z. et al. Laminin-521 promotes rat bone marrow mesenchymal stem cell sheet formation on light-induced cell sheet technology. Biomed. Res. Int. 2017, 9474573 (2017).

58. Liu, C. et al. Light-induced cell alignment and harvest for anisotropic cell sheet technology. ACS Appl. Mater. Interfaces 9, 36513-36524 (2017).

59. Wang, $X$. et al. Visible-light-responsive surfaces for efficient, noninvasive cell sheet harvesting. ACS Appl. Mater. Interfaces 9, 28250-28259 (2017).

60 . $\mathrm{Na}$, J. et al. Harvesting of living cell sheets by the dynamic generation of diffractive photothermal pattern on PEDOT. Adv. Funct. Mater. 27, 1604260 (2017).

61. Guillaume-Gentil, O. et al. pH-controlled recovery of placenta-derived mesenchymal stem cell sheets. Biomaterials 32, 4376-4384 (2011).

62. Kang, Y., Ren, L. \& Yang, Y. Engineering vascularized bone grafts by integrating a biomimetic periosteum and $\beta$-TCP scaffold. ACS Appl. Mater. Interfaces 6, 9622-9633 (2014).

63. Kim, A. Y. et al. Effect of gelatin on osteogenic cell sheet formation using canine adipose-derived mesenchymal stem cells. Cell Transpl. 26, 115-123 (2017).

64. Wang, F., Hu, Y., He, D., Zhou, G. \& Yang, X. Regeneration of subcutaneous tissue-engineered mandibular condyle in nude mice. J. Craniomaxillofac. Surg. 45, 855-861 (2017).

65. Ito, A. et al. Construction and harvest of multilayered keratinocyte sheets using magnetite nanoparticles and magnetic force. Tissue Eng. 10, 873-880 (2004). 
66. Ito, A., Ino, K., Kobayashi, T. \& Honda, H. The effect of RGD peptide-conjugated magnetite cationic liposomes on cell growth and cell sheet harvesting. Biomaterials 26, 6185-6193 (2005).

67. Ito, A., Jitsunobu, H., Kawabe, Y. \& Kamihira, M. Construction of heterotypic cell sheets by magnetic force-based 3-D coculture of HepG2 and NIH3T3 cells. J. Biosci. Bioeng. 104, 371-378 (2007).

68. Zhang, W. et al. Magnetically controlled growth-factor-immobilized multilayer cell sheets for complex tissue regeneration. Adv. Mater. 29, 1703795 (2017).

69. Chen, G. et al. Application of the cell sheet technique in tissue engineering. Biomed. Rep. 3, 749 (2015).

70. Owaki, T. \& Shimizu, T. Cell sheet engineering for regenerative medicine: current challenges and strategies. Biotechnol. J. 9, 904-914 (2014).

71. Katsuhisa, M., Rie, U., Kenichi, N. \& Teruo, O. Cell sheet approach for tissue engineering and regenerative medicine. J. Control. Release 190, 228-239 (2014).

72. Kirby, G. T. S., Michelmore, A., Smith, L. E., Whittle, J. D. \& Short, R. D. Cell sheets in cell therapies. Cytotherapy 20, 169 (2018).

73. Moschouris, K., Firoozi, N. \& Kang, Y. The application of cell sheet engineering in the vascularization of tissue regeneration. Regen. Med. 11, rme-2016-0059 (2016).

74. Masuda, S. \& Shimizu, T. Three-dimensional cardiac tissue fabrication based on cell sheet technology. Adv. Drug Deliv. Rev. 96, 103-109 (2016).

75. Iwata, T. et al. Cell sheet engineering and its application for periodontal regeneration. J. Tissue Eng. Regen. Med. 9, 343-356 (2015).

76. Sato, M, Yamato, M, Hamahashi, K, Okano, T. \& Mochida, J. Articular cartilage regeneration using cell sheet technology. Anat. Rec. (Hoboken) 297, 36-43 (2014).

77. $\mathrm{Ma}, \mathrm{D}$. et al. Engineering scaffold-free bone tissue using bone marrow stromal cell sheets. J. Orthop. Res. 28, 697-702 (2010).

78. Shimizu et al. Bone tissue engineering with human mesenchymal stem cell sheets constructed using magnetite nanoparticles and magnetic force. J. Biomed. Mater. Res. B 82B, 471-480 (2007).

79. Ueyama, Y. et al. Maxillofacial bone regeneration with osteogenic matrix cell sheets: an experimental study in rats. Arch. Oral Biol. 72, 138-145 (2016).

80. Gómez-Barrena, E. et al. Bone fracture healing: cell therapy in delayed unions and nonunions. Bone 70, 93-101 (2015).

81. Nakamura, A. et al. Cell sheet transplantation of cultured mesenchymal stem cells enhances bone formation in a rat nonunion model. Bone 46, 418-424 (2010).

82. Shimizu, T. et al. The regeneration and augmentation of bone with injectable osteogenic cell sheet in a rat critical fracture healing model. Injury 46, 1457-1464 (2015)

83. $\mathrm{Ma}, \mathrm{D}$. et al. Enhancing bone formation by transplantation of a scaffold-free tissue-engineered periosteum in a rabbit model. Clin. Oral Implants Res. 22 1193-1199 (2011).

84. Zhou, Y. et al. Combined marrow stromal cell-sheet techniques and highstrength biodegradable composite scaffolds for engineered functional bone grafts. Biomaterials 28, 814-824 (2007).

85. Ueha, T. et al. Utility of tricalcium phosphate and osteogenic matrix cell sheet constructs for bone defect reconstruction. World J. Stem Cells 7, 873-882 (2015).

86. Lin, J. et al. Enhancing bone regeneration by combining mesenchymal stem cell sheets with $\beta$-TCP/COL-I scaffolds. J. Biomed. Mater. Res. B Appl. Biomater. 106, 2037-2045 (2017)

87. Akahane, M. et al. Implantation of bone marrow stromal cell sheets derived from old donors supports bone tissue formation. Tissue Eng. Regen. Med. 15, 1-12 (2018).

88. Shan, X. \& Hu, D. Bone engineering by cell sheet technology to repair mandibular defects. Exp. Ther. Med. 14, 5007-5011 (2017).

89. Liu, Y. et al. Integration of a calcined bovine bone and BMSC-sheet 3D scaffold and the promotion of bone regeneration in large defects. Biomaterials 34, 9998-10006 (2013).

90. Long, T. et al. The effect of mesenchymal stem cell sheets on structural allograft healing of critical sized femoral defects in mice. Biomaterials 35, 2752-2759 (2014).

91. Subbiah, R. \& Guldberg, R. E. Materials science and design principles of growth factor delivery systems in tissue engineering and regenerative medicine. Adv. Healthc. Mater. 8, e1801000 (2018).

92. Qi, Y. et al. Combining mesenchymal stem cell sheets with platelet-rich plasma gel/calcium phosphate particles: a novel strategy to promote bone regeneration. Stem Cell Res. Ther. 6, 256 (2015).
93. Thompson, E. M. et al. Recapitulating endochondral ossification: a promising route to in vivo bone regeneration. J. Tissue Eng. Regen. Med. 9, 889-902 (2015).

94. Dang, P. N. et al. Endochondral ossification in critical-sized bone defects via readily implantable scaffold-free stem cell constructs. Stem Cells Transl. Med. 6, 1644 (2017).

95. Asakawa, N. et al. Pre-vascularization of in vitro three-dimensional tissues created by cell sheet engineering. Biomaterials 31, 3903-3909 (2010).

96. Ren, L. et al. Preparation of three-dimensional vascularized MSC cell sheet constructs for tissue regeneration. Biomed. Res. Int. 2014, 301279 (2014).

97. Ren, L., Kang, Y., Browne, C., Bishop, J. \& Yang, Y. Fabrication, vascularization and osteogenic properties of a novel synthetic biomimetic induced membrane for the treatment of large bone defects. Bone 64, 173-182 (2014).

98. Domenico, R., Beatrice, N. \& Enrico, C. The role of pericytes in angiogenesis. Int. J. Dev. Biol. 55, 261-268 (2011).

99. Mendes, L. F. et al. Perivascular-like cells contribute to the stability of the vascular network of osteogenic tissue formed from cell sheet-based constructs. PLOS ONE 7, e41051 (2012).

100. Zhang, $H$. et al. Construction of vascularized tissue-engineered bone with a double-cell sheet complex. Acta Biomater. 77, 212-227 (2018).

101. Nakano, K. et al. Promotion of osteogenesis and angiogenesis in vascularized tissue-engineered bone using osteogenic matrix cell sheets. Plast. Reconstr. Surg. 137, 1476-1484 (2016).

102. Ma, D. et al. Prefabrication of axially vascularized bone by combining $\beta$-tricalciumphosphate, arteriovenous loop, and cell sheet technique. Tissue Eng. Regen. Med. 13, 579-584 (2016).

103. Li, N. et al. Periosteum tissue engineering-a review. Biomater. Sci. 4, 1554-1561 (2016).

104. Zhang, D. et al. Engineering biomimetic periosteum with $\beta$-TCP scaffolds to promote bone formation in calvarial defects of rats. Stem Cell Res. Ther. 8, 134 (2017).

105. Ahmed, T. A. \& Hincke, M. T. Strategies for articular cartilage lesion repair and functional restoration. Tissue Eng. Part B Rev. 16, 305-329 (2010).

106. Ge, Y., Yi, G. Y., Xu, Z., Lu, Y. \& Fu, W. The application of sheet technology in cartilage tissue engineering. Tissue Eng. Part B Rev. 22, 114-124 (2016).

107. Mitani, G. et al. The properties of bioengineered chondrocyte sheets for cartilage regeneration. BMC Biotechnol. 9, 1-11 (2009).

108. Hamahashi, K. et al. Studies of the humoral factors produced by layered chondrocyte sheets. J. Tissue Eng. Regen. Med. 9, 24-30 (2015).

109. Kaneshiro, N. et al. Bioengineered chondrocyte sheets may be potentially useful for the treatment of partial thickness defects of articular cartilage. Biochem. Biophys. Res. Commun. 349, 723-731 (2006).

110. Yano, F. et al. A novel disease-modifying osteoarthritis drug candidate targeting Runx1. Ann. Rheum. Dis. 72, 748-753 (2013).

111. Chen, D. et al. Osteoarthritis: toward a comprehensive understanding of pathological mechanism. Bone Res. 5, 16044 (2017).

112. Takaku, Y. et al. In vivo cell tracking by bioluminescence imaging after transplantation of bioengineered cell sheets to the knee joint. Biomaterials 35, 2199-2206 (2014).

113. Shimizu, R. et al. Repair mechanism of osteochondral defect promoted by bioengineered chondrocyte sheet. Tissue Eng. Part A 21, 1131-1141 (2015).

114. Son, J., Bang, M. S. \& Park, J.-K. Hand-maneuverable collagen sheet with micropatterns for 3D modular tissue engineering. ACS Biomater. Sci. Eng. 5, 339-345 (2018).

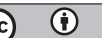

Open Access This article is licensed under a Creative Commons Attribution 4.0 International License, which permits use, sharing, adaptation, distribution and reproduction in any medium or format, as long as you give appropriate credit to the original author(s) and the source, provide a link to the Creative Commons license, and indicate if changes were made. The images or other third party material in this article are included in the article's Creative Commons license, unless indicated otherwise in a credit line to the material. If material is not included in the article's Creative Commons license and your intended use is not permitted by statutory regulation or exceeds the permitted use, you will need to obtain permission directly from the copyright holder. To view a copy of this license, visit http://creativecommons. org/licenses/by/4.0/.

(c) The Author(s) 2019 